\title{
Methodology for the process of validating qualifications in the Basque language and their adaptation to the Common European Framework of Reference for Languages (CEFR)
}

\author{
Iñaki Pikabea Torrano \\ i.pikabea@ehu.es \\ José Francisco Lukas Mujika \\ if.lukas@ehu.es \\ Universidad del País Vasco, Spain \\ Neus Figueras Casanovas \\ nfiguera@xtec.cat \\ Generalitat de Catalunya, Spain
}

\begin{abstract}
In the Basque Country there are currently more than 140,000 people with accredited qualifications that certify their knowledge of Euskara (Basque Language). These qualifications have been issued by a number of official bodies dependent on the Basque Government, but had not been validated against each other until recently.

In order to validate these qualifications and adapt them to the Common European Framework of Reference for Languages, a group of experts were commissioned by the Basque Government to undertake a study conducive to this end. This paper outlines the methodology and conclusions of that study.
\end{abstract}

Keywords: methodology, evaluation, qualifications, Euskara (the Basque language), the European Framework of Reference, validations.

\section{INTRODUCTION}

In the Basque Country (a region comprising part of the north of Spain and the southwest of France) there are currently over 140,000 people who possess one or several of the more than 20 different qualifications that accredit knowledge of the Basque language (Euskara) at different levels. These qualifications are required to be able to work as government administration personnel (teaching staff, healthcare employees, etc.).

Since 1998 there have been demands from the general public for a single system and a common approach to accrediting competence in the Basque language. In 2006, those responsible for such affairs at the Vice-Ministry for Language Policy of the Basque 
Government contacted the authors of this paper and stressed the need to have an accreditation system for knowledge of the Basque language which was capable of agglutinating the different models of such knowledge and/or the routes that can be taken to certify it, while employing a unified approach based on the Common European Framework of Reference for Languages (CEFR) (Council of Europe, 2001, 2003, 2004, 2009).

It was also understood that the work undertaken in European bodies such as ALTE (Association of Language Testers in Europe) or EALTA (European Association for Language Testing and Assessment) should be incorporated, as should the opinions of recognized experts from the field of language assessment (Alderson, 2006; Cizek \& Bunch, 2007; Downing \& Haladyna, 2006; Verdía, Conde, De Samblanc \& Cassany, 2002; Zieky \& Livingston, 2008). In a first phase, the commission of experts drew up a report (Figueras, Pikabea \& Lukas, 2008) describing the work done and its results, and also including recommendations for improvement of the different tests. An outcome of this process was the approval by the Basque Government of the framework for the validation of qualifications and accredited certificates of knowledge in Basque and their adaptation to the CEFR. This framework was incorporated into a number of legislative decrees, culminating in the decree ${ }^{1}$ which defined the validations and drew parallels between the various qualifications and certificates of knowledge of the Basque language (Pikabea, Lukas, Figueras, 2009).

Through this system of accreditations and validations practically all the qualifications in Euskara (a total of 22, with some having been granted since 1975) have become officially recognized within the CEFR. In this way, the validations between the different qualifications and certificates are recognized, as is their relationship with the four levels of the European Framework. The equivalences of the qualifications and certificates from IVAP ${ }^{2}$, HABE, Osakidetza, Ertzaintza, the Basque Government's Education, Universities and Research Department, the Royal Academy of the Basque Language (Euskaltzaindia), the Department of Education of the Government of Navarre and the Escuelas Oficiales de Idiomas (Government-run Language Schools) were established with the B-1, B-2, C-1 and C-2 levels of the European Framework. 
Three years later, the Basque Government once again contacted the authors of this paper and asked for a second report. The different systems of evaluation had been updated by the various bodies involved after the publication of the above mentioned decree, and it was necessary to assess to what extent the changes responded to the recommendations of the 2008 Report. This second report was finalized in 2011 (Figueras, Pikabea, Lukas, 2011). In this article the research procedures followed in the first and second reports are briefly outlined, together with a series of suggestions put forward on the basis of the different analyses and observations. The authors have adopted a general approach, as detailed results and data for the different qualifications and organizations need to remain confidential.

\section{OBJECTIVES AND LIMITATIONS}

The objectives proposed were the following:

1. Analysis of current systems for the accreditation of knowledge of the Basque language amongst adults.

2. Establishment of a common set of specifications for fluency in the language that would enable the objective comparison of levels, tests and the degree of benefit drawn from the various systems for certification amongst adults.

3. Proposal for adaptations considered necessary, taking the CEFR criteria and levels as a basis.

4. If possible, the design of a table of equivalences for the various certifications of knowledge of Basque amongst adults.

5. Monitoring of adaptations, 4 years on.

\section{METHODOLOGY}

\section{III.1. First phase (2006-2008)}

Based on the Council of Europe's recommendations for harmonizing exams with the CEFR levels as described in the Manual for Relating Examinations to the CEFR 
(familiarization, specification, standardization of judgments, empirical validation), the steps and calendar to be followed were set out and a protocol of actions drawn up. These were then forwarded to all the bodies participating in the project, with the request to provide the researchers - within a period of one month - with:

1. a certain number of test forms (corresponding to the last three years)

2. the completed questionnaires designed to this end

3. a certain number of candidates' written scripts and oral performances, following set requirements

That is, on the one hand, protocols or questionnaires were drawn up for the analysis of the examinations and, on the other, expert judges were selected and used to assess the test tasks and the candidates' scripts and performances in relation to the CEFR levels.

The following procedures were followed:

Questionnaire analysis. The Questionnaire was developed based on the Forms included in the 2003 Council of Europe Manual and included questions on: 1) general description of the exam;2) drafting and administration of the tests; 3) correction and scoring; 4) analysis of data and a later review; 5) qualitative-technical analysis of the tests; and 6) estimated global level of each examination in CEFR terms.

System of judges. Judges were selected from amongst expert teachers, teacher trainers and item writers in the Basque country, and the procedures followed in their training and standardization were also those recommended in the 2003 Council of Europe Manual, including: 1) familiarization of the judges (a total of 30) with the CEFR descriptors; 2) judges' analysis and evaluation of the samples of oral and written production of the examinees (a total of 39 written comprehension tasks, 16 oral comprehension tasks, 36 pieces of written production from the students and another 34 items of oral production from the students).

The data thus gathered were examined thoroughly and, as a conclusion, a report was drawn up in 2008. Table 1 reflects the possible comparability of qualifications, as well as the adaptations needed to conform to the CEFR levels.

To this end, the following criteria were used: 
- Analysis of test data provided by their devisers (Lukas, 1998)

- Qualitative-technical analysis of tests

- Analysis of the tests and CEFR level assignments by the judges

When required, a scale of grey tones was used to indicate, beside each qualification, the areas in which the qualification in question had to be adjusted in order to have a comprehensive, integrated equivalence with the $\mathrm{CEFR}^{3}$ levels.

Abbreviations:
wc: written comprehension
we: written expression
oc: oral comprehension
oe: oral expression

\section{Interpretation and positions of colours:}

\begin{tabular}{|l|l|}
\hline Same column & Equivalence in general terms \\
\hline & Absence of specific test \\
\hline & Does not reach required level \\
\hline
\end{tabular}

Table 1 shows a graphical summary of the conclusions drawn from research in the 2008 report. This summary was considered extremely useful by examination bodies, as it showed where adjustments were necessary, and extremely helpful by government administration bodies, as it helped decision-making.

Numbers 1-5 in the Organization column refer to the five exam-providing institutions in the Basque country, their names not being given for the sake of confidentiality. 
Table 1. Summary of equivalences to the CEFR (2008 Report).

\begin{tabular}{|c|c|c|c|c|c|c|c|c|c|c|}
\hline \multicolumn{11}{|c|}{ CEFR LEVELS } \\
\hline \multirow{5}{*}{$\begin{array}{l}\text { ORGANISATION } \\
1\end{array}$} & \multirow{5}{*}{ 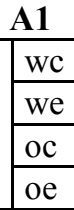 } & \multirow{3}{*}{$\begin{array}{l}\text { A2 } \\
\text { wc } \\
\text { we } \\
\end{array}$} & \multicolumn{2}{|c|}{ B1 } & \multicolumn{2}{|c|}{ B2 } & \multicolumn{2}{|c|}{ C1 } & \multicolumn{2}{|c|}{ C2 } \\
\hline & & & \multirow{4}{*}{$\begin{array}{c}\text { Certificate } \\
\text { A }\end{array}$} & $\mathrm{wc}$ & \multirow{4}{*}{$\begin{array}{c}\text { Cer } \\
\text { B }\end{array}$} & $\mathrm{wc}$ & \multirow{4}{*}{$\begin{array}{c}\text { Cer } \\
\text { C }\end{array}$} & wc & \multirow{4}{*}{$\begin{array}{c}\text { Cer } \\
\text { D }\end{array}$} & \multirow{3}{*}{$\frac{\mathrm{wc}}{\mathrm{we}}$} \\
\hline & & & & we & & we & & we & & \\
\hline & & $\mathrm{oc}$ & & $\mathrm{oc}$ & & oc & & oc & & \\
\hline & & oe & & oe & & oe & & HAn & & oe \\
\hline & & & & & & & & & & \\
\hline \multirow{4}{*}{2} & wc & wc & \multirow{4}{*}{$\begin{array}{c}\text { Certificate } \\
\text { A }\end{array}$} & wc & \multirow{4}{*}{$\begin{array}{c}\text { Cer } \\
\text { B }\end{array}$} & we & \multirow{4}{*}{$\begin{array}{c}\text { Cer } \\
\text { C }\end{array}$} & we & \multirow{4}{*}{$\begin{array}{c}\text { Cer } \\
\text { D }\end{array}$} & wc \\
\hline & we & we & & we & & we & & we & & we \\
\hline & oc & $\mathrm{oc}$ & & $\mathrm{oc}$ & & $\mathrm{oc}$ & & $\mathrm{oc}$ & & $\mathrm{oc}$ \\
\hline & oe & oe & & oe & & oe & & oe & & oe \\
\hline & & & & & & & & & & \\
\hline \multirow{4}{*}{3} & wc & $\mathrm{wc}$ & & $\mathrm{wc}$ & \multirow{4}{*}{$\begin{array}{c}\text { Cer } \\
\text { A }\end{array}$} & wc & \multirow{4}{*}{$\begin{array}{c}\text { Cer } \\
\text { B }\end{array}$} & wc & & wc \\
\hline & we & we & & we & & we & & we & & we \\
\hline & $\mathrm{oc}$ & $\mathrm{oc}$ & & $\mathrm{oc}$ & & oc & & $\mathrm{oc}$ & & $\mathrm{oc}$ \\
\hline & oe & oe & & oe & & oe & & oe & & oe \\
\hline & & & & & & & & & & \\
\hline \multirow{4}{*}{4} & $\mathrm{wc}$ & $\mathrm{wc}$ & \multirow{4}{*}{$\begin{array}{c}\text { Certificate } \\
\text { A }\end{array}$} & wc & \multirow{4}{*}{$\begin{array}{c}\text { Cer } \\
\text { B }\end{array}$} & wc & \multirow{4}{*}{$\begin{array}{c}\text { Cer } \\
\text { C }\end{array}$} & wc & & wc \\
\hline & we & we & & we & & we & & we & & we \\
\hline & oc & $\mathrm{oc}$ & & $\mathrm{oc}$ & & $\mathrm{oc}$ & & $\mathrm{oc}$ & & $\mathrm{oc}$ \\
\hline & oe & oe & & oe & & oe & & oe & & oe \\
\hline & & & & & & & & & & \\
\hline \multirow{4}{*}{5} & wc & $\mathrm{wc}$ & \multirow{4}{*}{$\begin{array}{c}\text { Certificate } \\
\text { A }\end{array}$} & $\mathrm{wc}$ & \multirow{4}{*}{$\begin{array}{c}\text { Cer } \\
\text { B }\end{array}$} & $\mathrm{wc}$ & \multirow{4}{*}{$\begin{array}{c}\text { Cer } \\
\text { C }\end{array}$} & $\mathrm{wc}$ & & $\mathrm{wc}$ \\
\hline & we & we & & we & & we & & we & & we \\
\hline & oc & oc & & $\mathrm{oc}$ & & $\mathrm{oc}$ & & $\mathrm{oc}$ & & $\mathrm{oc}$ \\
\hline & oe & oe & & oe & & oe & & oe & & $\mathrm{oe}$ \\
\hline
\end{tabular}

\section{III.2.Second phase (2011)}

A number of years after these proposals for validated qualifications were first put forward (2008), the Department of Language Policy of the Basque Government commissioned a review and the monitoring of the changes and improvements made by each body responsible for setting examinations in the Basque language.

In the process monitored for this research, a protocol of activities was drawn up again and then remitted to all those bodies participating in the project, the certifying bodies or organizations being requested to ensure that such examinations for the validation of qualifications should:

- provide the same number of tests (corresponding to recent examination announcements) for each of the levels examined 
- complete the questionnaires designed with this aim

- designate people with a thorough knowledge of the tests to be interviewed by the researchers

\section{Technical qualitative analysis of the tests}

Apart from the EALTA Recommendations, other points taken into account for the technical analysis of the tests were, on the one hand, the usual criteria for item development and, on the other, the recommendations made in the 2008 report.

\section{Monitoring of suggested recommendations}

The recommendations made in the Report of the Commission of Experts on the Validation of Basque Language Qualifications and their Adaptation to CEFR (2008) were reviewed to determine whether or not each recommendation had been taken into account.

\section{Questionnaire analysis}

The questionnaires sent to examination providers were aimed at collecting information about five different aspects, namely:

1. Drawing up the tests

2. Medium-term adjustments

3. Completing the tests

4. Technical analysis of the tests

\section{Commentaries}

For each affirmative response some evidence was required to accredit its veracity. And each negative response also required an explanation.

\section{Interviews with representatives of the board}

The information gathered and analyzed, both through questionnaires constructed ad hoc as well as through the technical qualitative analysis of the tests, was completed with interviews with the experts and/or those responsible for the various examinations of the 
institutions involved in the research. In all, 10 people from five institutions were interviewed.

Figure 1 shows the different sources of information employed in order to reach the conclusions drawn in this report.

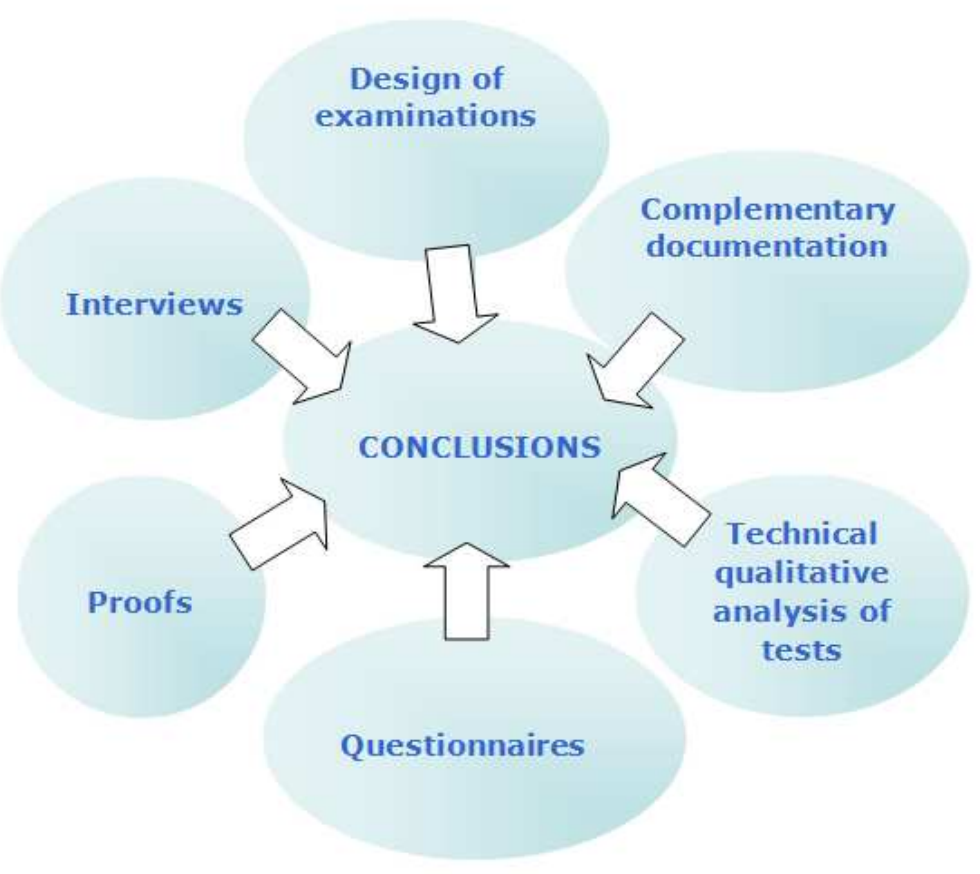

Figure 1. Triangulation of the different sources of information.

\section{RESULTS}

The results and conclusions were included in two reports (2008 and 2011).

\section{Team of evaluators}

The teams of evaluators are very heterogeneous. Evaluation is considered to be a speciality that is sufficiently demanding and painstaking to have stable dedicated teams of evaluators in each institution.

\section{Designs and protocols}

A clear improvement and greater professionalization in test development and analysis are observed. In most cases this was already the starting point. A very high level was seen in the measurement tools that were analyzed and in the processes and documentation supporting them. 


\section{Comparison of requirements}

The comparison of requirements for qualifications which, theoretically, accredit the same CEFR level was not reviewed. This would be a very important experimental study which would make it possible to identify possible imbalances between qualifications at the same level issued by different departments.

\section{Validation of qualification at CEFR level}

No institution claims to have experimental data that guarantee that its qualifications do, in fact, correspond to CEFR levels, whereas they all state that they follow the Framework descriptors strictly. However, no field research has been carried out to allow an informed comparison of evaluation processes for other languages in Spain or in other countries.

\section{Qualifications at C2 level}

An analysis of the two existing qualifications that currently accredit level $\mathrm{C} 2$ reveals a different conception of the evaluation process for this level. While one particular body may present a concept similar to that used at previous levels but at a greater level of difficulty, the other body may interpret the certification as the final part of an ongoing evaluation process, where the work done during the course (a prerequisite to be able to sit the exam) is taken into consideration. This provides candidates with two ways of being evaluated, with different requirements.

\section{Unnecessary evaluation processes}

It has been observed that in some cases candidates have to pass tests which, in reality, do not provide data of interest. This happens in certain evaluations where the candidate, before completing the examination that will provide him/her with an accreditation, is required to sit a pre-test, the results of which are only used to decide whether the candidate is ready to sit the examination or not.

\section{Variety of examination formats}

The designs of the evaluations that were analyzed are complete and their content fulfils the criteria for validity. However, it has been observed that, in some cases, the training 
given to the students for the acquisition of Basque is conditioned by the type of exam. As a consequence, it becomes too restricted, as it is too dependent on the exam format. This is why some bodies propose a greater variety of tests in their examinations, thereby avoiding an over-repetitive format.

\section{CONCLUSIONS AND IMPLICATIONS}

The proposal for the validation of qualifications in Basque and for their adaptation to the CEFR levels also included several suggestions to improve the design and uses of the tests. The suggestions were addressed to the management or administrative bodies and referred to topics or lacunas needing short- or medium-term consideration with the goal of enhancing the accreditation processes. Amongst the most notable suggestions, the following are worth mentioning:

\section{Open/restricted exam sessions}

Some bodies have both open and restricted examination sessions, but there is no empirical evidence about the level of competence of the candidates, whether they are comparable or not. This is a task that will have to be addressed in the future.

\section{Examples of classified oral/written productions}

What the authors propose is the establishment of a classified collection of samples, to act as a reference for all accrediting organizations, given that this will reduce the risk of there being significant differences amongst the sample collections of different bodies. Thus, just one collection of reference samples will help to obviate there being different levels of requirements from one organization to another at any one CEFR level.

\section{Inter-institutional Technical Commission}

The report proposed the creation of an inter-institutional technical commission to debate and agree on those technical aspects that are of concern to the evaluation processes, with the goal of avoiding overlaps (exam calendars, etc.) or disparity of criteria.

\section{Team of evaluators}

Test development is a sophisticated operation. In many organizations teams of item writers have a short existence, and in others item development is commissioned to 
outside contractors. In order to guarantee the necessary coordination and coherence, it is recommended that each institution take total control of the process, including the design of the tests, in order to foster higher quality.

\section{Qualifications at C2 level}

It is recommended that the two institutions certifying C2 and currently using totally different procedures reach an agreement as to which formula is the fairest and most appropriate.

\section{Accreditation bodies}

Concern arises from not knowing which organizations will, in the future, be officially allowed to carry out the evaluation and accreditation of candidates' knowledge and acquisition of the Basque language, as well as the possible consequences thereof.

\section{Unnecessary evaluation processes}

In section 4 of this paper we have mentioned that some institutions require the candidate to sit a pre-test prior to the final official test. The data available show that the results obtained in the oral and written comprehension sections of the pre-test that the candidates take in their study centers match those obtained in the final examination. In view of this evidence, we strongly recommend that the accrediting institutions focus on the assessment of productive skills (oral and written production), thus avoiding unnecessary duplication of costs incurred by the Administration.

\section{Request for advice}

While the authors were drawing up their reports, certain departments requested advice on evaluation topics that would help clear up doubts that might arise. At an administrative level, it would be useful to have a team of experts who could also respond to this type of internal requests.

\section{Evaluation of oral comprehension}

In general, the models for the evaluation of oral production are apparently similar across institutions: the examinee listens to an audio accompanied by items that have to be answered correctly, but what format of audio text should the candidate be provided with? Should it be a monologue, a conversation, a clip from a real interview, a sequence 
from a TV programme, a standard language production... or what? Unification of criteria within each organization or body and, if possible, on an inter-institutional level is important.

\section{Statistical analysis of the tests}

Pilot testing needs to be an indispensable condition prior to the final application of a certificate test. It is equally important to analyze how the test items worked after their final application. Besides justifying the technical quality of the tests employed, these analyses will be used to create the bank of calibrated items to guarantee the quality of future examinations. Finally, the bodies that administer a preliminary test should analyze its predictive validity, as well as its reliability.

\section{Establishment of standards or cut scores}

It would also be useful to set down some procedure for establishing such scoring methods, although this may involve modifying current legislation in some cases.

\section{Linguistic normalization and accreditation}

The reports also raise the question of a possible clash between the goals of language normalization in the Basque Country and the system of accreditation. Possible contradictions would have to be detected and, in such cases, decisions deemed opportune would need to be taken.

\section{Resources and criteria for disabled candidates}

The drawing up of a general, single norm of compulsory compliance is recommended, and this would have to comply with and respond to the content of State legislation corresponding to that of the International Convention on the Rights of Persons with Disabilities.

\footnotetext{
Notes

${ }^{1}$ Decree 297/2010 in the Official Gazette of the Government of the Basque Country.

2 IVAP: Basque Institute for Public Administration; HABE: Institute for the Acquisition of and Literacy in the Basque Language by Adults; Osakidetza: the Basque National Health Service, Ertzaintza: the Basque Police Force.
} 
Methodology of the process of validation of qualifications in the Basque language and of their adaptation to the Common European Framework of Reference for Languages (CEFR)

${ }^{3}$ This example serves as a rough guide, the names of the institutions and the qualifications awarded having been omitted. Not all institutions issue qualifications at all CEFR levels.

\section{REFERENCES}

Alderson, J.C. et al. 2006. Analyzing tests of reading and listening in relation to the CEF: the experience of the Dutch CEF construct project. Language Assessment Quarterly. 3(1) 3-30.

Cizek, G. and Bunch, M. 2007. Standard Setting. A Guide to Establishing and Evaluating Performance Standards on Tests. Sage Publications

Council of Europe. 2001. Common European Framework of Reference for Languages: Learning, teaching, assessment. Cambridge: Cambridge University Press.

Council of Europe. 2003. Relating Language Examinations to the Common European Framework of Reference for Languages: Learning, Teaching, Assessment (CEF): Manual Preliminary Pilot Version. Strasbourg: Language Policy Division.

Council of Europe. 2004. Reference Supplement to the Preliminary Pilot Version of the Manual for Relating Language Examinations to the Common European Framework of Reference for Languages: Learning, Teaching, Assessment. Strasbourg: Language

Council of Europe. 2009. Manual for relating examinations to the CEFR. Available at: http://www.coe.int/t/dg4/linguistic/manuel1_en.asp (last accessed 22-11-2011)

Downing, S.M and Haladyna, T.M. (eds.). 2006. Handbook of test development. London: Lawrence Erlbaum Associates.

Figueras, N., Pikabea, I. and Lukas; J.F. 2008. Informe de la Comisión de Expertos sobre convalidación de titulaciones de euskara y adecuación al MCER. Gobierno Vasco: Viceconsejería de Política Lingüística (unpublished).

Figueras, N., Pikabea, I. and Lukas, J.F. 2011. Informe de seguimiento de la Comisión de Expertos sobre convalidación de titulaciones de euskara y adecuación al MCER. Gobierno Vasco: Viceconsejería de Política Lingüística (unpublished). 
Lukas, J.F. 1998. Análisis de items y de tests con ITEMAN. Leioa: Servicio de Publicaciones de la Universidad del País Vasco.

Pikabea, I., Lukas, J.F and Figueras, N. 2009. "Proceso de comparabilidad de titulaciones de euskara y adecuación al Marco Común Europeo de Referencia (MCER)". Revista de Investigación Educativa. 27(2) 469-486.

Verdía, E., Conde, G., De Samblanc and Cassany, D. 2002. "Marco común europeo de referencia y Portfolio de las lenguas.”, Mosaico, 9, monográfico. Revista para la Promoción y Apoyo a la Enseñanza del Español.

Zieky, M. P. and Livingston, S. 2008. Cut scores: A Manual For Setting Standards Of Performance On Educational And Occupational Tests. ETS.

Received: 10 May 2013

Accepted: 24 October 2013

Cite this article as:

Pikabea, I., Lukas, J.F. \& Figueras, N. 2014. "Methodology of the process of validation of qualifications in the Basque language and their adaptation to the Common European Framework of Reference for Languages (CEFR)”. Language Value 6 (1), 1-14. Jaume I University ePress: Castelló, Spain. $\quad$ http://www.e-revistes.uji.es/languagevalue. http://dx.doi.org/10.6035/LanguageV.2014.6.2

ISSN 1989-7103

Articles are copyrighted by their respective authors 